\title{
Identification and molecular characterisation of a fibrinogen binding protein from Streptococcus iniae. Justice CF Baiano ${ }^{1}$, Reiny A Tumbol ${ }^{1}$, Aarti Umapathy ${ }^{1}$ and Andrew C Barnes*1,2
}

Address: ${ }^{1}$ Aquatic Animal Health Laboratory, Centre for Marine Studies, The University of Queensland, St. Lucia, 4072, Australia and ${ }^{2}$ School of Integrative Biology, The University of Queensland, St. Lucia, 4072, Australia

Email: Justice CF Baiano - j.baiano@uq.edu.au; Reiny A Tumbol - r.tumbol@uq.edu.au; Aarti Umapathy - s4105611@student.uq.edu.au; Andrew C Barnes* - a.barnes@uq.edu.au

* Corresponding author

Published: 23 April 2008

BMC Microbiology 2008, 8:67 doi:10.1186/147|-2180-8-67
Received: 24 December 2007

Accepted: 23 April 2008

This article is available from: http://www.biomedcentral.com/|47|-2/80/8/67

(C) 2008 Baiano et al; licensee BioMed Central Ltd.

This is an Open Access article distributed under the terms of the Creative Commons Attribution License (http://creativecommons.org/licenses/by/2.0), which permits unrestricted use, distribution, and reproduction in any medium, provided the original work is properly cited.

\begin{abstract}
Background: Binding of serum components by surface M-related proteins, encoded by the emm genes, in streptococci constitutes a major virulence factor in this important group of organisms. The present study demonstrates fibrinogen binding by $S$. iniae, a Lancefield non-typeable pathogen causing devastating fish losses in the aquaculture industry and an opportunistic pathogen of humans, and identifies the proteins involved and their encoding genes.
\end{abstract}

Results: Fibrinogen binding by $S$. iniae significantly reduced respiratory burst activity of barramundi peritoneal macrophages in primary cultures compared to BSA-treated or untreated controls, indicating a potentially important role for fibrinogen binding cell-surface proteins in avoiding phagocytic attack in fish. We describe a novel emm-like gene, simA, encoding a $57 \mathrm{kDa}$ fibrinogen binding M-like protein in S. iniae. These SiM proteins and their corresponding tetrameric structures from some sequevar types $(\sim 230 \mathrm{kDa})$ bound fibrinogen in Western blots. $\operatorname{sim} A$ was most closely related (32\% identity) to the $\operatorname{dem} A$ gene of $S$. dysgalactiae. Genome walking and sequencing determined the genetic organization of the simA region had similarities to the $\mathrm{mgrC}$ regulon in GCS and to $S$. uberis. Moreover, a putative multigene regulator, $m g x$ was orientated in the opposite direction to the $\operatorname{sim} A$ gene in common with S. uberis, but contrary to findings in GAS and GCS. In GAS, diversity among emm-genes and consequent diversity of their M-related proteins results in substantial antigenic variation. However, an extensive survey of $S$. iniae isolates from diverse geographic regions and hosts revealed only three variants of the gene, with one sequevar accounting for all but two of the 50 isolates analysed.

Conclusion: These proteins play a role in avoiding oxidative attack by phagocytic cells during infection of fish by S. iniae, but genetic diversity amongst these key surface proteins has not yet arisen. This lack of diversity coupled with a functional role in macrophage resistance suggests that these proteins may constitute important targets for future vaccines against $S$. iniae in fish. 


\section{Background}

One of the most devastating diseases to warm water finfish aquaculture is caused by Streptococcus iniae. First isolated from a captive Amazon River dolphin, Inia geoffrensis, in 1976, S. iniae has caused outbreaks of disease in Israel, Australia, Japan, and the United States [1]. The economic losses attributed to $S$. iniae are estimated to be up to \$US10 million annually in the US and over $\$$ US100 million globally [2]. Infection in farmed fish usually presents as small red lesions on the skin followed by exophthalmia, and it is found systemically in the blood, kidneys and brain [1]. It is also a known zoonotic pathogen causing a handful of infections to date mainly in elderly people. $S$. iniae is a beta-haemolytic species that does not belong to any Lancefield group $[3,4]$.

It is well established that other streptococcal species such as S. pyogenes (GAS), S. equi subsp. zooepidemicus (GCS), and S. dysgalactiae subsp. equisimilis (GCS/GGS) possess M or M-like proteins [5-8]. These proteins are located on the surface of the bacterial cell and are considered in GAS to be the dominant virulence factor allowing evasion of phagocytosis and host cell attachment [9]. M proteins are coiled-coil proteins $[9,10]$ characterised by having a signal sequence followed by a hypervariable region, a central region containing a number of repeats, and a cell wall anchor motif [10].

The genes upstream and downstream of the $\mathrm{emm}$ gene vary from group to group and within species. In GAS, the multigene regulator gene, $m g a$, is upstream of the $\mathrm{emm}$ gene and a C5a peptidase gene is downstream. However, some strains of GAS can also have an emm-related protein gene and an enn gene [6]. Variations in the emm gene region of the genome in GCS and GGS have also been noted where the multigene regulator, $m g c$, is upstream of the emm gene, but no other emm-like genes are found [6]. Instead, the $c p d B$ gene is either present or absent between the emm gene and the rel gene.

One of the functions of the $\mathrm{M}$ protein is the binding of fibrinogen [9,11-13]. In strains of $S$. dysgalactiae, the M protein has also been reported to bind other blood components such as serum albumin, IgG, IgA, and plasminogen [13]. Ability to bind fibrinogen is recognised as a major factor in resistance to phagocytosis $[9,11,14]$

In this paper, we describe for the first time the emm-like genes, sim $A$ and $\operatorname{sim} B$, from a Lancefield-untypeable Streptococcus species - Streptococcus iniae. In other streptococci, M-like proteins are highly diverse contributing to substantial antigenic diversity, however in a survey of 50 isolates from disparate hosts and geographical origin, only 3 variants of the sim gene were identified in S. iniae. The genetic organization in the vicinity of the sim genes is similar to other streptococci, including a multigene regulator upstream with a putative toxic anion resistance gene downstream. The SiM proteins encoded by the simA and $\operatorname{sim} B$ genes bind fibrinogen and we demonstrate that fibrinogen binding by $S$. iniae reduces respiratory burst activity in barramundi peritoneal macrophages indicating a likely role in phagocytic evasion and virulence in teleost fish.

\section{Results \\ Fibrinogen binding by S. iniae}

Wild-type Streptococcus iniae QMA0076 and QMA0072 were capable of binding biotin-labelled human fibrinogen in vitro as evidenced by fluorescence microscopy of cells counter-labelled with avidin conjugated FITC (Figure 1). This was corroborated for strain QMA0076 by an independent dot-blot assay in which whole cells incubated with biotin-labelled fibrinogen and extensively washed were spotted onto PVDF membrane that was subsequently probed with alkaline phosphatase-conjugated avidin (Figure 2a). QMA0141 did not bind significant quantities of labelled fibrinogen by either method (Figures 1 and 2a). Interestingly, fibrinogen binding was only observed when cells were cultured on blood agar or grown in barramundi (Lates calcarifer, Bloch) serum, and not when grown in vegetable peptone broth (Figure 2a). Preincubating with fresh barramundi plasma prior to incubation with biotinylated fibrinogen reduced fibrinogen binding ability, but only marginally (Figure $2 \mathrm{~b}$ )

\section{Effect of Fibrinogen binding on activation of barramundi peritoneal leucocytes}

To investigate the role of fibrinogen binding by $S$. iniae, the effect of pre-incubating S. iniae QMA0072 with fibrinogen on subsequent phagocytosis and respiratory burst in barramundi peritoneal leucocytes was investigated. Fibrinogen binding by QMA0072 significantly decreased subsequent phagocytosis-induced respiratory burst in barramundi peritoneal leucocytes when compared to controls pre-incubated with the same concentration of BSA or in PBS alone (Figure. 3).

\section{S. iniae emm-like (sim) genes}

In order to find genes for putative fibrinogen binding proteins in $S$. iniae a homology cloning strategy was employed using a number of previously published and novel primers designed based on streptococcal emm and emm-like genes (Table 1). The previously published ALL M primer pair (Table 1) enabled sequencing of the full length sim ( Streptococcus iniae emm-like) gene. Primers for genome walking were designed to determine the true sequence of the gene for the extreme 5' and 3' end nucleotides since the ALL M primer pair introduced artefactual nucleotides (spacer region and encoding amino acids MA at the 5 ' end and KRKEEN at the 3 ' end) to the initially 

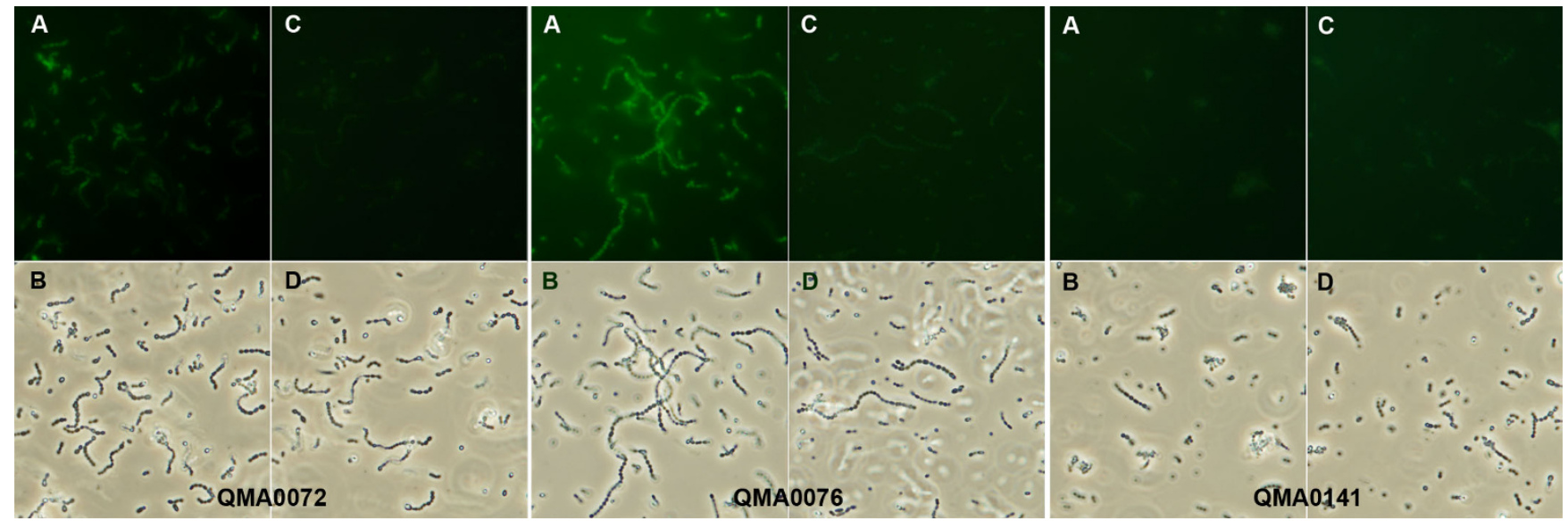

\section{Figure I}

Fluorescence and phase contrast micrographs of $S$. iniae showing binding of biotinylated fibrinogen. Strains QMA0072, QMA0076 and QMA00 I4I were incubated with biotinylated human fibrinogen, extensively washed and subsequently labelled with FITC-conjugated streptavidin. In each case panel A) indicates bacteria incubated with biotinylated fibrinogen, extensively washed and then stained with streptavidin-FITC under fluorescence, whilst B) is the same field photographed under phase contrast. Panel C) indicates control bacteria, incubated in PBS, extensively washed and stained with streptavidinFITC to detect any non-specific binding of streptavidin, or autofluorescence whilst $D$ ) is the same field observed under phase contrast. For fluorescence microscopy, all fields were exposed manually at ISO800 for I.3 seconds whilst phase contrast fields were captured using automatic exposure.

deduced sequence. The full length of the $\operatorname{sim} A$ gene was determined to be 1566 bp encoding a 521 amino acid protein in most strains (Figure 4), however, the protein for isolate QMA0072 had one amino acid insertion, and the sim gene for isolate QMA0141 (encoded by $\operatorname{sim} B$ ) was 579 amino acids (Table 3 ). The respective molecular masses of the proteins (with signal peptides) for isolates QMA0072, QMA0076, and QMA0141 were 57,589, 57,467 , and 63,667 Da respectively. The mature proteins have molecular masses of 53,416,53,303, and 59,446 Da respectively. There were changes to the amino acid sequence at the 3 ' end of the nucleotide sequence encoding for KRKEEE. Sequencing of the simA gene of $S$. iniae followed by translation from strain QMA0076 revealed that it was distinct from the other known $\mathrm{M}$ and $\mathrm{M}$-like protein types from $S$. pyogenes, S. suis, S. equi subsp. equi, $S$. dysgalactiae, and S. uberis. Sequence alignment of the different types of sim gene products from $S$. iniae with their closest matching counterpart, the demA gene product from $S$. $d \gamma$ sgalactiae, are presented in Figure 4.

\section{Organisation of genes in the vicinity of the sim genes of S. iniae}

Genome walking allowed the determination of the genes immediately surrounding the $\operatorname{sim} A$ gene and their relative translational directions. A probable ribosomal binding site with sequence AGGAG was found 11 bases upstream of the start of transcription of the simA gene (Figure 5). A putative regulatory protein binding site 45 nucleotides in length was found with a recognition site very similar to that found in the promoter regions of the emm and $\operatorname{scp} A$ genes in GAS [15] (Figure 5). Inverted repeats that occur between the ends of the simA gene and telX are likely to be a putative rho-independent transcriptional terminator (Figure 5).

At the $5^{\prime}$ end of the simA gene ( $261 \mathrm{nt}$ upstream) is an ORF of $1488 \mathrm{nt}$ encoding a 495 amino acid protein that shares $39 \%$ identity to sequences of Mgc from S. dysgalactiae subsp. equisimilis (GCS) and 34\% identity to Mga for $S$. pyogenes (GAS) (Figure 6). Due to the level of homology, this gene has been designated $m g x$ (multigene regulator of Lancefield group unknown streptococci) and the encoded protein is therefore Mgx. The $m g x$ gene is orientated in the opposite direction to the simA gene. This region of the genome is therefore also named $m g r X$ (multigene regulon-like genomic segment in Lancefield group unknown streptococci).

At the $3^{\prime}$ end of the simA gene, (110 nt downstream) is a gene, orientated in the opposite direction, with high identity $(81 \%$; similarity of $93 \%$ at the amino acid level) to the tellurite resistance/toxic anion resistance gene telA from $S$. pyogenes MGAS8232 (Figure 7). This gene of $1251 \mathrm{nt}$ encodes a protein of 416 amino acids and has been designated as telX. Another 20 nucleotides upstream from telX is an ORF of $885 \mathrm{nt}$ encoding a 294 amino acid protein which is most closely related to hypothetical gene 
A

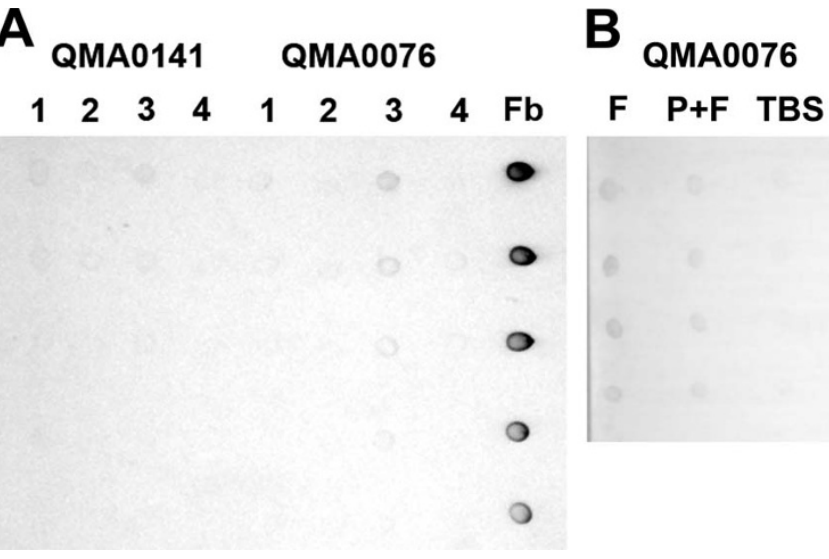

Figure 2

Dot blots showing binding of biotinylated fibrinogen by S. iniae. Strains QMA0076 and QMA0 14I were incubated with biotinylated fibrinogen, washed and transferred to PVDF, then membranes were probed with streptavidin-alkaline phosphatase conjugate and developed with NBT/BCIP. Panel A) Lanes I and 2 comprised $5 \mu$ cells grown in vegetable peptone, whilst lanes 2 and 3 contained $5 \mu$ cells grown in barramundi serum. Cells were harvested and washed in TBS before being incubated with biotinylated human fibrinogen (Lanes I and 3) or TBS (lanes 2 and 4) for 20 min, prior to extensive washing and transfer onto PVDF membrane for subsequent detection. Fb indicates serial two-fold dilutions of biotinylated fibrinogen commencing at $2.5 \mu \mathrm{g} / \mathrm{mL}$. Panel B) shows serial $2 \times$ dilutions of $5 \mu$ l cells diluted in TBS. Lane F, cells incubated first with TBS then with biotinylated fibrinogen before transfer to the membrane. Lane P+F, cells incubated with barramundi plasma followed by biotinylated fibrinogen, Lane TBS, cells incubated twice in TBS.

Spy_0159 from S. pyogenes M1 GAS with 40\% identity and $63 \%$ similarity (Figure 7). This gene in $S$. iniae has been called $\operatorname{sihA}(\underline{S}$. iniae hypothetical gene A).

A further 110 nucleotides upstream from the start of $\sin A$ is a probable start for a purA-like gene encoding adenylosuccinate synthase (EC 6.3.4.4), although an alternative start codon $305 \mathrm{nt}$ upstream would encode a protein with greater similarity to that from $S$. pyogenes rather than $S$. suis.

It was found that the genes $m g x, \operatorname{sim} A$, and telX were similar to genes found in other streptococcal species. However, unlike in GAS, GCS and GGS, and as only found thus far in S. uberis [16], the $m g x$ gene is orientated in the opposite direction relative to the simA gene (Figure 8).

\section{Diversity of sim genes in S. iniae}

In the Group A Streptococci (GAS), diversity of the M proteins accounts for significant antigenic variations and constitutes a major obstacle to vaccine development. By using

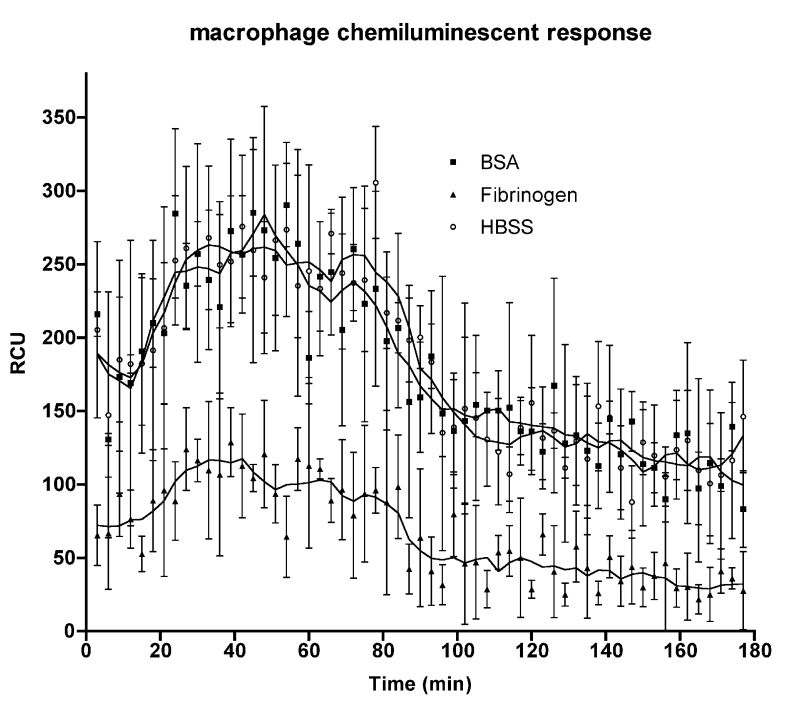

Figure 3

Effect of fibrinogen binding on activation of barramundi macrophages by S. iniae. S. iniae isolate QMA0072 harvested from blood agar was incubated with fibrinogen, BSA or HBSS and the respiratory burst was measured by luminol-enhanced chemiluminescence.

the PRE SIM and POST SIM primer pair, an expected PCR product of 2048 bp was produced when tested on an additional 49 isolates (Table 2 ) with only two exceptions. Isolate QMA0072, which had an insertion in the simA gene, produced a PCR product of $2051 \mathrm{bp}$ and QMA0141 produced a larger product of $2180 \mathrm{bp}$. The nucleotide and amino acid sequences for isolates QMA0076 and QMA0072 were identical except for the insertion of three nucleotides ( 1 aa residue) (Figure 4 ). The gene sequence for isolate QMA0141 was most divergent having 100\% amino acid residue identity for the first 35 residues and $100 \%$ similarity for the first 41 residues. This also confirms the theoretical position of where the signal sequence is cleaved to produce the mature SiM protein (Figure 4). This gene was approximately $10 \%$ larger than the simA gene and was designated $\operatorname{sim} B$. The nucleotide sequence identity of the simA gene in all isolates tested was $100 \%$. The length of the intergenic spacer regions upstream and downstream of the $\operatorname{sim} A$ gene in all isolates was the same size, except for isolate QMA0141 ( $\operatorname{simB}$ ), which had a larger sequence downstream. Variations in the upstream intergenic spacer sequence were limited. Thus, the same genetic organization was present in all of the isolates tested.

\section{mgx sequence analysis}

The $m g x$ gene encodes the protein Mgx which contains helix-turn-helix structures (Figure 6). Sequence alignment with other multigene regulators from $S$. pyogenes 
Table I: Primers used in this study.

\begin{tabular}{|c|c|c|}
\hline Primer & Sequence (5'-3') & Reference \\
\hline ALL MF & GGGGGGGGATCCATAAGGAGCATAAAAATGGCT & Podbielski et al., |99| \\
\hline ALL MR & GGGGGGGAATTCAGCTTAGTTTTCTTTCTTTGCG & Podbielski et al., |991 \\
\hline SP6 & GCTATTTAGGTGACACTATAGAAT & Invitrogen \\
\hline T7 & GTAATACGACTCACTATAGGG & Invitrogen \\
\hline SIM F & AATTAATGAAGCTGGAGTGCTCT & This study \\
\hline SIM WF & GGGAGGCTTCGCTGACATTTATTTCC & This study \\
\hline SIM W3F & TACGGCCGTAAACGCAAAGAGGAAGAA & This study \\
\hline SIM R & GCTTCCACAAGTTTTTCTTTGTCA & This study \\
\hline SIM $2 R$ & GTAGATAGGCTTTGATTTTCACTA & This study \\
\hline $\operatorname{SIM} 2 \mathrm{~F}$ & GATACGCTTCAAAGTTCTTACTAT & This study \\
\hline SIM $3 F$ & GCTGCTAAGATCAACATGCC & This study \\
\hline SIM WR & ACCTATAATCAGGTTCTAAATTCGTGGC & This study \\
\hline SIM W2R & GGAAGATGTGTCCATTGTTTGATGAGATG & This study \\
\hline PRE SIM & TTGTTGGGTGGAAAAAAGATC & This study \\
\hline POST SIM & AAACTCAGGGACCAAAAAATTG & This study \\
\hline SIM3F RC & GGCATGTTGATCTTAGCAGC & This study \\
\hline $\mathrm{MI} I \mathrm{IF}$ & CAAAATGATCACATCAGC & This study \\
\hline ESIM 20F & CACCATGGCTAAACAAATCAAAGC & This study \\
\hline ESIM I542R & TTCTTCCTCTTTGCGTTTACGG & This study \\
\hline
\end{tabular}

and S. dysgalactiae subsp. dysgalactiae showed that there was a high level of conservation in the HTH-4 helix-turnhelix domain from residues 106-125 with these Mgx homologues. This is a common feature of all multigene regulator proteins found in GAS and GCS/GGS and from some unfinished genome projects and is necessary for transcriptional activation of virulence factors [17]. The multigene regulator in $S$. iniae was more divergent as a whole, than those of other streptococcal groups, especially in the other known helix-turn-helix region (HTH-3) (Figure 6). Putative Mgx protein binding motifs were found in the spacer regions upstream of the $\operatorname{sim} A$ or $\operatorname{sim} B$ genes in all isolates sequenced (Figure 9). Variations in Mgx binding sites between isolates may be due to differences in the Mgx protein in different isolates. Like the binding sites in other species, it is 45 bp long and overlaps the -35 promoter box [15]. The region on the right hand side of the consensus sequence $\left(C_{R}\right)$ is more conserved than that from the left $\left(C_{L}\right)$ [15] (Figure 9).

\section{SiM protein sequence analysis}

The N-terminal of the major SiM protein type from isolate QMA0076 has a probable signal sequence cleavage site between amino acids 41 and 42 resulting in a mature protein of 480 amino acids with a molecular mass of $\sim 53 \mathrm{kDa}$ (Figure 4). For isolate QMA0141, the signal peptide cleavage point is also between residues 41 and 42 resulting in a mature protein of 538 residues with a molecular mass of $\sim 59 \mathrm{kDa}$ (Figure 4). In the C terminal end of all of the SiM proteins is the conserved Gram positive cell wall anchor motif LPSTG [18]. The N-terminal region of the SiM protein types had very similar signal peptides, but the first residues of the mature protein differed significantly while there was a high level of conservation at the $\mathrm{C}$ terminal ends of the proteins. This indicates that selective pressures have been exerted upon the exposed $\mathrm{N}$ terminal parts of the protein.

Analysis by the Garnier algorithm [19] for isolate QMA0076 predicted that $77.2 \%$ of the protein was alphahelical. For isolates QMA0072 and QMA0141, the predicted values were $77.1 \%$ and $77.4 \%$ respectively for their SiM proteins.

Analysis by the COIL program [20,21] with a window length of 28 predicted that the protein from isolate QMA0076 (with signal sequence) has two coiled-coil segments from residues $79-174$ and 181-454 with a probability of 1.00 for each segment. This is a similar result to that of Vasi et al. (2000)[18] who identified M-like proteins from $S$. dysgalactiae. By weighting the first and fourth residues in the heptad repeats a probability of 1.00 was gained for residues 91 to 449. Similarly, for isolate QMA0072 two coiled-coil segments from residues 79174 and 196-455 with a probability of 1.00 for each segment were predicted. Weighting the first and fourth residues in the heptad repeats gave a prediction with a probability of 1.00 for two segments from residues 91186 and 213-450.

The SiM protein from isolate QMA0141 showed a probability of 1.00 that there was a coiled-coil structure from residues 154-512 with a weighted heptad, and coiledcoils at residues 151-231 and 238-512 when an unweighted heptad was used. 
Table 2: Strains used in this study.

\begin{tabular}{|c|c|c|}
\hline Strain & Source & Geographic Origin \\
\hline QMA0070 & Lates calcarifer & Townsville, Queensland, Australia \\
\hline QMA007I & Lates calcarifer & Cairns, Queensland, Australia \\
\hline QMA0072 & Lates calcarifer & Townsville, Queensland, Australia \\
\hline QMA0076 & Lates calcarifer & Townsville, Queensland, Australia \\
\hline QMA0077 & Lates calcarifer & Townsville, Queensland, Australia \\
\hline QMA0078 & Lates calcarifer & Cairns, Queensland, Australia \\
\hline QMA0079 & Lates calcarifer & Cairns, Queensland, Australia \\
\hline QMA0080 & Lates calcarifer & Lake Argyle, Western Australia, Australia \\
\hline QMA008I & Lates calcarifer & Lake Argyle, Western Australia, Australia \\
\hline QMA0082 & Lates calcarifer & Lake Argyle, Western Australia, Australia \\
\hline QMA0083 & Lates calcarifer & Lake Argyle, Western Australia, Australia \\
\hline QMA0084 & Pteropus conspicillatus & Western Australia, Australia \\
\hline QMA0087 & Lates calcarifer & Lake Argyle, Western Australia, Australia \\
\hline QMA0109 & Lates calcarifer & Northern Territory, Australia \\
\hline QMAOII2 & Lates calcarifer & Northern Territory, Australia \\
\hline QMA0I23 & Lates calcarifer & Northern Territory, Australia \\
\hline QMA0I25 & Lates calcarifer & Northern Territory, Australia \\
\hline QMA0I26 & Lates calcarifer & Northern Territory, Australia \\
\hline QMA0I30 & Homo sapiens & Canada \\
\hline QMA0I3I & Homo sapiens & Canada \\
\hline QMA0I33 & Homo sapiens & USA \\
\hline QMA0I34 & Homo sapiens & USA \\
\hline QMA0I35 & Homo sapiens & USA \\
\hline QMA0137 & Homo sapiens & USA \\
\hline QMA0I38 & Homo sapiens & USA \\
\hline QMA0I39 & Unknown fish & Canada \\
\hline QMAOI40 & Inia geoffrensis & USA \\
\hline QMA0I4I & Inia geoffrensis & USA \\
\hline QMA0I43 & Lates calcarifer & Northern Territory, Australia \\
\hline QMA0I45 & Lates calcarifer & Northern Territory, Australia \\
\hline QMA0I50 & Lates calcarifer & Northern Territory, Australia \\
\hline QMA0I5I & Lates calcarifer & Northern Territory, Australia \\
\hline QMA0I52 & Lates calcarifer & Northern Territory, Australia \\
\hline QMA0I56 & Lates calcarifer & New South Wales, Australia \\
\hline QMA0I58 & Lates calcarifer & South Australia, Australia \\
\hline QMA0I59 & Lates calcarifer & South Australia, Australia \\
\hline QMA0I60 & Lates calcarifer & South Australia, Australia \\
\hline QMA0166 & Lates calcarifer & Bowen, Queensland, Australia \\
\hline QMA0167 & Lates calcarifer & Bowen, Queensland, Australia \\
\hline QMA0169 & Lates calcarifer & Kelso, New South Wales, Australia \\
\hline QMA0I70 & Lates calcarifer & Bowen, Queensland, Australia \\
\hline QMA0I7I & Lates calcarifer & Bowen, Queensland, Australia \\
\hline QMA0I73 & Lates calcarifer & South Australia, Australia \\
\hline QMA0I77 & Lates calcarifer & Northern Territory, Australia \\
\hline QMA0I82 & Lates calcarifer & Northern Territory, Australia \\
\hline QMA0I84 & Lates calcarifer & Northern Territory, Australia \\
\hline Cll-5b-88 & Channa striata & Bangkok, Thailand \\
\hline KFPI73 & Oncorhynchus mykiss & Upper Galilee, Israel \\
\hline KFP404 & Oncorhynchus mykiss & Upper Galilee, Israel \\
\hline $21-96(2)$ & Oncorhynchus mykiss & Réunion Island \\
\hline
\end{tabular}

The SiM proteins also share repeat elements that are a feature of M proteins. QMA0072 and QMA0076 contained five repeat elements of the residue sequence AELE. In contrast, the SiM protein from isolate QMA0141 contained five pairs of repeat elements represented by KEEE, AELE,
AKVAELEKAL, ELEA, and KAELEK. Large peptide sequence motifs conserved across all SiM proteins are HEAIRSAGLE between the coils, the signal peptide, and the $\mathrm{C}$ terminal end which has few variations over the last $\sim 255$ residues of the protein. 
!

\begin{tabular}{|c|c|}
\hline QMa0072 & 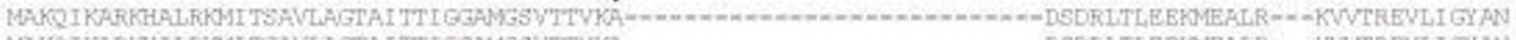 \\
\hline QMa0076 & 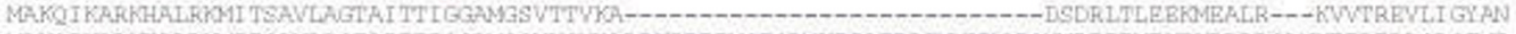 \\
\hline $\cosh 0141$ & 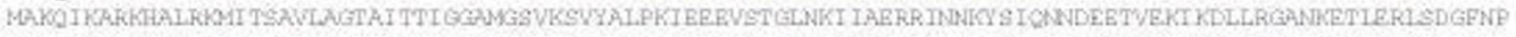 \\
\hline dema & 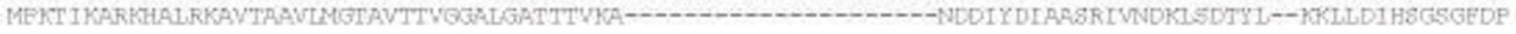 \\
\hline Seva0072 & --DKTQRLTWENKKMEETLKSKVERINEAGGVLLSKKDKD----LNEABAKITDLNSKR! \\
\hline QMa0076 & N-NPRFGFAI-_- \\
\hline $\operatorname{cosho141}$ & 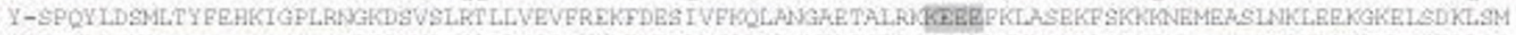 \\
\hline demi & 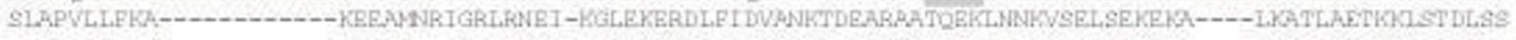 \\
\hline $\cos 0072$ & 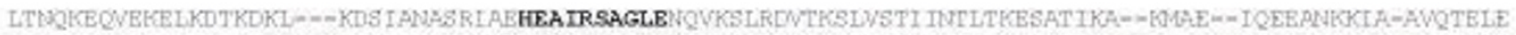 \\
\hline QMA0076 & 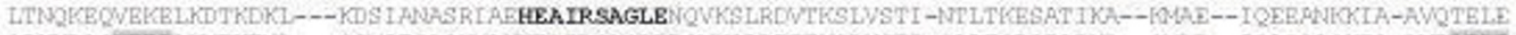 \\
\hline $\operatorname{cosh0141}$ & 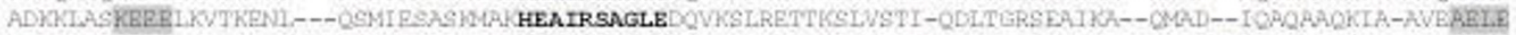 \\
\hline dema & 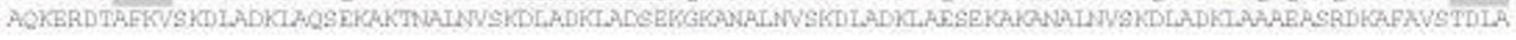 \\
\hline QMA0072 & 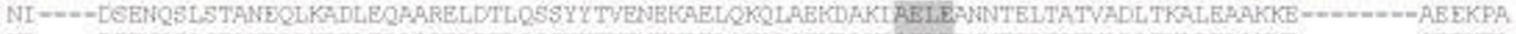 \\
\hline QMA0076 & 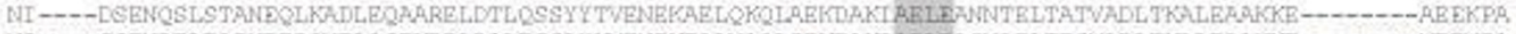 \\
\hline CMa0141 & 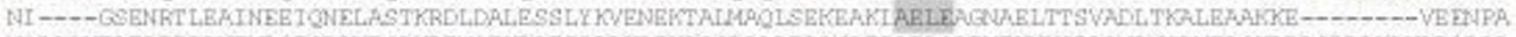 \\
\hline $\operatorname{dem} A$ & 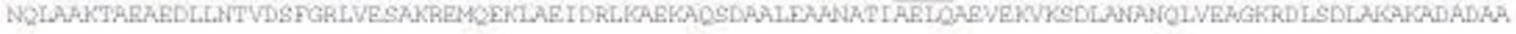 \\
\hline QMa0072 & 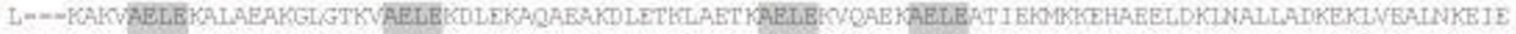 \\
\hline QMa0076 & 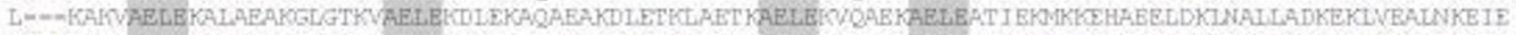 \\
\hline cesho141 & 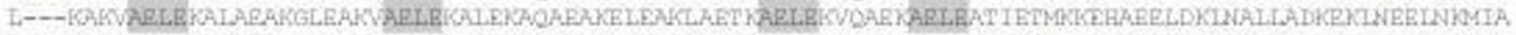 \\
\hline demi & 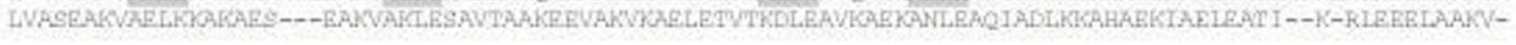 \\
\hline SMA0072 & 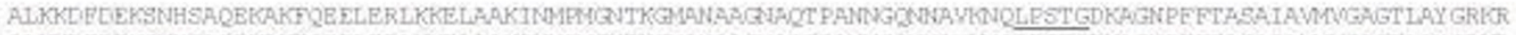 \\
\hline QNA0076 & 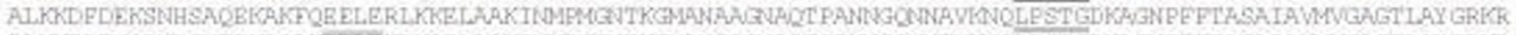 \\
\hline CMa0141 & 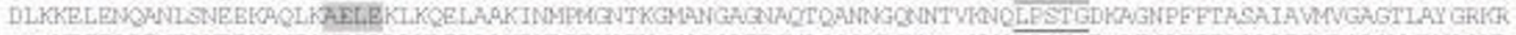 \\
\hline demi & 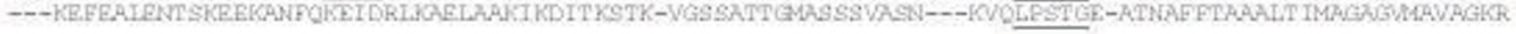 \\
\hline 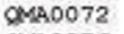 & - \\
\hline SMA0076 & KEEE \\
\hline $\cos$ & $19=$ \\
\hline
\end{tabular}

\section{Figure 4}

Amino acid sequence alignment of $S$. iniae $M$ proteins with $S$. dysgalactiae demA gene product (CAB654 I I). Putative signal cleavage site between amino acids $4 I$ and 42 is indicated with an arrow. Repeat regions are highlighted. The putative hinge between the two coils is in bold type and the conserved LPXTG membrane anchor near the C-terminal is underlined.

PAGE and Western blot analysis of expressed SiM proteins Analysis by SDS-PAGE of non-reduced expressed proteins (Fig. 10A) showed that there were bands present which were different to that contained in the control E. coli lysate. Prominent protein bands were present at $\sim 230 \mathrm{kDa}$ from isolates QMA072 and QMA076; but not for isolate QMA0141.

Western blotting was used to detect the fibrinogen binding proteins from these lysates. Binding of biotinylated fibrinogen followed by detection with alkaline phosphatase conjugated streptavidin in Western blots of SDS-
PAGE separated lysates from E. coli expressing recombinant SiM proteins showed that the SiM proteins from isolates QMA0072 and QMA0076 appeared as monomeric of $\sim 57 \mathrm{kDa}$ as expected and also as tetramers of $\sim 230 \mathrm{kDa}$. A band that weakly bound fibrinogen was also observed that appears to be a dimer at $115 \mathrm{kDa}$. The SiM protein from isolate QMA0141 appeared as bands at 64 $\mathrm{kDa}$ and $\sim 255 \mathrm{kDa}$ and does not appear to bind fibrinogen as strongly as that from isolates QMA0072 and QMA0076 (Fig. 10B). The formation of tetramers has been observed in SiM proteins from other species [12].

Table 3: $S$. iniae sim gene lengths and $M$ protein identity.

\begin{tabular}{|c|c|c|c|c|c|c|}
\hline Strain & Length (nt, aa) & BLAST-P result & Identity (\%) ${ }^{\mathrm{a}}$ & Similarity (\%) ${ }^{\mathrm{b}}$ & Gene & sim sequevar \\
\hline QMA0072 & 1569,522 & S. dysgalactiae demA gene & 32 & 49 & $\operatorname{sim} A$ & $\mathrm{~A} 2$ \\
\hline QMA0076 & 1566,521 & S. dysgalactiae demA gene & 32 & 50 & $\operatorname{sim} A$ & $\mathrm{Al}$ \\
\hline QMA0I4I & 1740,579 & S. dysgalactiae subsp. dysgalactiae M-like protein & 31 & 48 & $\operatorname{sim} B$ & $\mathrm{BI}$ \\
\hline
\end{tabular}

a,b $-\%$ according to BLASTP analysis. 
TTAAAATTGCTCATAAAAATGTAACTATTTTAATTATAACTATTATAACATTTAATAAAA 60 GGTPATAAGCTAANAATRCCATTAAAAAACTGCGCPTTATTCTCATTTAAAACTCATATA 120 $-35$ TACTAATYTPATAGATTGACCCAACTMGCCTCAAAGAGCAGCAAGATTGCAATCATAAT 180 $-10$ ATTAGGAAGAAAATAAGGAGAACCCTAAACATGCCTAAACAAATCAAAGCCCGTAAACAT 240 RBS IS A $\mathrm{K}$ Q GCCTTGCGCAAAATGATCACATCAGCAGTCCTTGCCGGAACAGCAATCACAACCATCGGT 300 $\begin{array}{lllllllllllllllllllll}A & I & R & K & M & I & T & S & A & V & L & A & G & T & A & I & T & T & I & G & 30\end{array}$ GGTGCAATGGGAAGCGTCACAACAGTAAAAGCGGATAGNGATAGATTMACCTIGGAAGAX 360

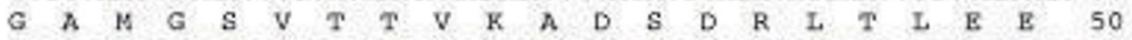
AAAATGGAAGCGTTAAGAAAGGTAGTTACTAGAGAAGTATTAATAGGTTATGCTRATAAT 420 $\begin{array}{lllllllllllllllllllll}K & M & E & A & I & R & K & V & V & T & R & B & V & L & I & G & Y & A & N & N & 70\end{array}$ AATCCAAGATTTGGTTPTTGGATGTCGTTACAACAATTAGAAAAAGAAATTGATAAAACC 480 $\begin{array}{lllllllllllllllllllll}N & P & R & F & G & F & W & M & S & I & Q & Q & I & E & K & E & I & D & K & T & 90\end{array}$ CAACGTTTAACTTGGGAAAATAAAAGAATGGAAGAGACTCTAAAAAGTAAAGTTGAAAGA 540 $\begin{array}{llllllllllllllllllllll}Q & \text { R } & \text { L } & \text { T } & \text { W } & \text { E } & \text { N } & \text { K } & \text { R } & \text { M } & \text { E } & \text { E } & \text { T } & \text { L } & \text { K } & \text { S } & \text { K } & \text { V } & \text { E } & \text { R } & 110\end{array}$ ATTAATGAAGCTGGAGTGCTCTTATCAAAGAAACAAAAAGATTTAAATGAAGCAGAAGCA 600 $\begin{array}{lllllllllllllllllllll}I & N & B & A & G & V & L & L & S & K & K & \& & K & D & L & N & E & A & B & A & 130\end{array}$ AAAATTACAGATCTTAATTCAAAACAAACGGATTTAACAAATCAAAAAGAACAAGTAGAA 660 $\begin{array}{lllllllllllllllllllll}K & \text { K } & T & D & L & N & S & K & \& & T & D & L & T & N & \& & K & E & \& & V & E & 150\end{array}$ AAAGA.ATTAAAAGATACTAAAGATAAACTTAAAGATTCGATTGCTAATGCTTCAAGGATT 320 $\begin{array}{lllllllllllllllllllll}K & E & I & K & D & T & K & D & K & I & K & D & S & I & A & N & A & S & R & I & 170\end{array}$ GCTGAGCATGAAGCAATTCGCTCAGCAGGTCTTGAAAATCAAGTGAAATCATTACGTGAT 780 $\begin{array}{lllllllllllllllllllll}A & E & H & E & A & I & R & S & A & G & L & E & N & Q & V & K & S & I & R & D & 190\end{array}$ GTAACAAAGTCACTTGTTTCAACTATCAATACTTTGACTAAAGAGTCAGCAACAATTAAA 840 $\begin{array}{lllllllllllllllllllll}V & T & K & S & L & V & S & T & I & N & T & I & T & K & E & S & A & T & I & K & 210\end{array}$ GCTAAAATGGCTGAAATTCAAGAAGAGGCTAATAAAAAAATTGCAGCAGTACAAACAGAA 900 $\begin{array}{lllllllllllllllllllll}\mathrm{A} & \mathrm{K} & \mathrm{K} & \mathrm{A} & \mathrm{E} & \mathrm{I} & Q & \mathrm{E} & \mathrm{E} & \mathrm{A} & \mathrm{N} & \mathrm{K} & \mathrm{K} & \mathrm{I} & \mathrm{A} & \mathrm{A} & \mathrm{V} & Q & \mathrm{~T} & \mathrm{E} & 230\end{array}$ TTAGAAAATATTGATAgTGAAAATCAAAGCCTATCTACAGCTAACGAGCAATTAAAAGCA 960

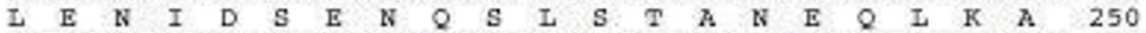
GATTTGGAACAAGCTGCACGAGAATTAGATACGCTTCAAAGTTCTTACTATACAGTAGAA 1020 $\begin{array}{lllllllllllllllllllll}D & I & E & Q & A & A & R & E & I & D & T & L & Q & S & S & Y & Y & T & V & E & 270\end{array}$ AATGAAAAGGCTGAACTTCAAAAACAATTGGCAGAAAAAGATGCTAAGATTGCGGAACTT 1080 $\begin{array}{llllllllllllllllllllll}N & E & K & A & \text { E } & \text { L } & Q & K & Q & \text { L } & \text { A } & \text { E } & \text { K } & \text { D } & \text { A } & \text { K } & \text { I } & \text { A } & \text { B } & \text { I } & 290\end{array}$ GAACCAAACAACACAGAATTAACACCAACTGTTGCTGATTTGACTAAACCATTAGAAGCG 1140

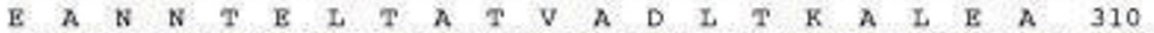
GCTAAGAAAGAAGCAGAAGAAAAACCTGCTCTTAAAGCTAAAGTTGCAGAATTAGAAAAA 1200

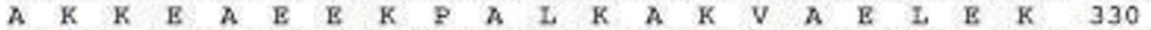
GCTCTMGCAGAAGCTAAAGGTTAGGGACTAAAGTTGCAGAACTTGAAAAAGACCTTGAG 1260 $\begin{array}{lllllllllllllllllllll}A & \text { I } & A & \text { B } & A & K & G & \text { L } & G & \text { T } & \text { K } & \text { V } & \text { A } & \text { B } & \text { L } & \text { B } & \text { K } & \text { D } & \text { L } & \text { B } & 350\end{array}$ AAAGCACAAGCAGAAGCTAAAGACCTTGAAACTAAACTAGCAGAAACAAAAGCTGAATTG 1320 $\begin{array}{llllllllllllllllllllll}K & A & \& & A & B & A & K & D & \text { L } & \text { E } & \text { T } & \text { K } & \text { L } & \text { A } & \text { E } & \text { T } & \text { K } & \text { A } & \text { E } & \text { L } & & 370\end{array}$ GAAAAAGTTCAAGCTGAAAAACCAGAACTTGAACCAACTATTGAAAAAATGAAGAAAGAG 1380 $\begin{array}{llllllllllllllllllllll} & E & K & V & Q & A & B & K & A & B & \text { L } & \text { B } & \text { A } & \text { T } & \text { I } & \text { E } & \text { K } & \text { M } & \text { K } & \text { K } & \text { E } & 390\end{array}$ CATGCTGAAGAGCTTGACAAACTAAATCCTCTTCTTCCTGACAAAGAAAAACTTGTCGAA 1440

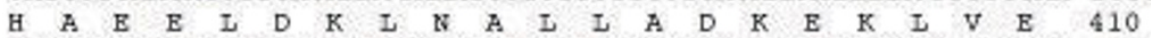
GCTTTGAACAAAGAAATCGAAGCGCTTAAGAAAGACTTTGACGAAAAATCAAACCATTCT 1500 $\begin{array}{llllllllllllllllllllll}A & I & N & K & E & I & E & A & L & K & K & D & F & D & E & K & S & N & \text { H } & S & 430\end{array}$ GCACAAGAAAAAGCTAAGTTCCAAGAAGAACTGGAACGCCTCAAAAAAGAATTGGCTGCT 1560

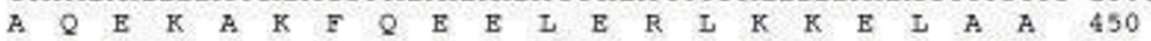
A.AGATCAACATGCCAATOGGCAACACCAAAGGCATGGCAAACGCTGCTGGAAACGCGCAA 1620 $\begin{array}{lllllllllllllllllllll}K & I & N & N & P & N & G & N & T & K & G & N & A & N & A & A & G & N & A & Q & 470\end{array}$ ACTCCAGCTAACAACGGTCAAAACAACGCTGTTAAGAACCAATTCCCATCAACAGGTGAT 1680

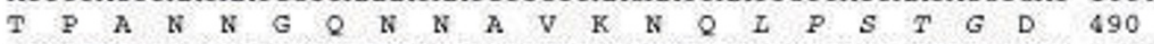
AAAGCAGGTAACCCATTCTTCACAGCAAGTGCTATCGCGGTTATGGTTGGAGCTGGTACT 1740

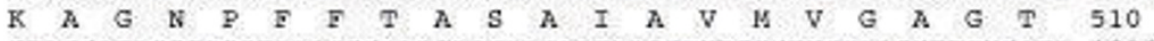
CTAGCATACGGCCGTAAACGCAAAGAGGAGATAAGCTTCCCTTGCAACCTTTMCATA 1800 $\begin{array}{llllllllllllll}I & A & Y & G & R & K & R & K & E & E & E & * & 521\end{array}$ GACACACCCCCTATAAGTCCACTGGACTTATAGGGGGTTTTGACATTCAAAACTCCTACT 1860 >>>>>>>>>>>>>>>>>> <<<<<<<<<<<<<<<

\section{Figure 5}

Nucleotide and amino acid sequences of $S$. iniae simA gene and SiM protein. Putative Mgx protein binding site is shaded, putative promoter sequences ( -10 and -35 boxes and ribosome binding site - RBS - sequence) are boxed, inverted repeats are highlighted by wedges, the membrane anchor is italicised, the stop codon is bolded and indicated by an asterisk. 
$\operatorname{Mg} x$

IIgC:

Mga

$\lg x$

MgC

Mga

MgX

Mgc

Mga

MgX

uge

uga

Mgx

IIGC

uga

$\operatorname{Mg} \mathrm{x}$

the

uga

Mgx

$\mathrm{MgC}$

Mga

MgX

MgC

uga

$\operatorname{tg} x$

Mge

Mas
MPSKKDLFSTQQLRELNL IKLLSQDKEAPDYKT--ICRQLDCSPITLQSELAHLSTPPGI MTHASKLETKQQWRELEL IAHLTEHSERMGYKDRELCKVENSTVSTLQACIAMLQEIESI M-YVSKLETSQQWRELKLISYLTENSNAIGVKDKELSKALNISULTLQSCLTMMQFUKEV

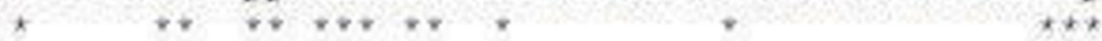

HTH-3

SSPPYIESHLTIDXHKAXGPQKLXQSVLLDRPTLRLUESPPPNECHNLDTLASNLPISLS GRITYEDGYLTIGYNDHCGLQEVYQRALRESQSLQLLSALFEKEFDSLEDLADALFISLS GGITYKDGYINIWYHQCCGLQEVYQKALRESPSLKLLELLFFRDFS SLEELREELFVSLS

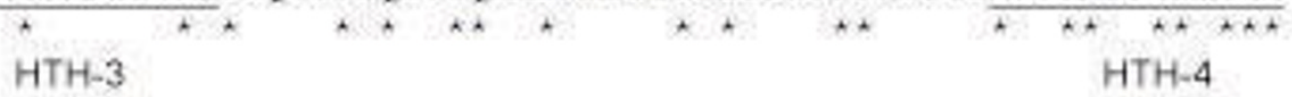

TLKRL IKRTNTYLKQTEDCKID IKQF IVGNEKQIRLFYLKYESEAYDKHDWPEDDLVSE TLKRLITRTNGYLKEEFGIKISTRPVMVGDEHHIRLFYLKYFSEAYTESEWPFAEIINQ TLKRLIKKTNTYLSHTEAISIVTSPVQVSGNERQIRLFYLKYTSEAYKISEWPFGDILNL

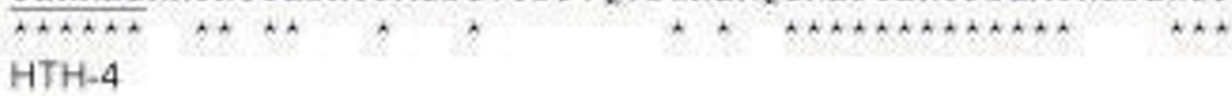

SALEDLIHLSAKQLDAPIDYSLLHHLKIMAGVHLVRESQGYRVN-DVYRLAQDLCHQLED NNLERL IALMAKQTDVPVNFALFOHLKILSGVNL IREOKGFTLNRKDKGLEHLEHKVLED KNCERLLSLLIKEVDVKVHPTLPQHLKILSGVNLIRXXKGXSCSXNNKKTSHRPSQL IQH

ESAPTDLHDKPETDPLEPLNCLALSEUPSAPPLEDVM- NEQKIE-LADEDNQKVDPHD SLEIMCL SALFALKYNQPLDARALAE IFSNYLNPALELGKLLQSDDSAREQTLSSHQMVE SSEIQDLSRLFYLKEGLHLDEYT IABMESNHLNDKLE IGCAFE I IN - QDPTSGGRQVTN

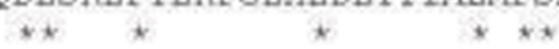

WSQLUT IEKGL PLEIANKDEICRHLHNAT ILGDYDIYENFL IYDYRKPPLDYFKSNYPD WIALLDKIEKSLQLSI SNKYELARHLQTTVILAEED ISANPL IYDYKKEXLKPFHKHXRV WIHLLDELE IKLNLSITNKYEVAVTLHNASVLNEEDITANYLLFDYKKSYLNFYQKEHRR

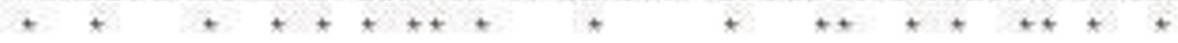

LWQSLCDS I EAT YDKKGVDHQDKDLNHML $Y$ LL INWDNL FMQL SNA I SKQKL LVIEKGSC IYDTELTYVEDLFALDHQEFNEGIRNHLLYCLEITWENLFLKISQSRRKLKLLVIERSYR. IYEAFVTSVEKLMOADNAQVSKEL INQLTYCFE TWENSFLKVNQKDEKVRLLVIERSYN

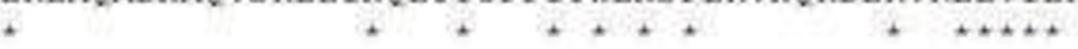

NVGQPLQGFAGQPFDITIHQEMD-- IKKAHIEGKXDLVLTDVSLEQIDGVDVXPFSQLV NYGNELKEYFGEFEEIISFDDLGNPKIDLL PLAKEYDVILTDVILEQNNHSEILFFNQUI SVGNFLKKYIGEFES ITNEDELDCLT IDLVEIEKQYDVIVTDVMVKSEELEIFFEYKII
$* * * *$
$* * * *$
*
** ***
$\star *$

PSIALAELNKHLKHKIQNREKLTS

PSVVADLTDELKVKVGED-KLPESVALNQUSTS

PEAIIDRLNEFLNYSETDNNYNKNLEAPSSSKSHSDKEVQKPDNSYKOATSS

$+\quad+\quad+$

\section{Figure 6}

Amino acid alignment of S. iniae Mgx protein with Mgc from S. dysgalactiae subsp. equisimilis and Mga from S. pyogenes. Identical residues are indicated with asterisks. Helix-turn-helix regions are underlined (after Vahling and Mclver, 2006). 


\begin{abstract}
teIX MSDFNEDIDAIANSSLSKTDKTTEIITDLPTNQTGQVAFFDKLSTEQQEAITAKVPALVD
LEIA MADFNEDIDQIADNAVVKTDKTTDIISDLPTDTNGOISFFEKLSADOQTAITAKAPALVD

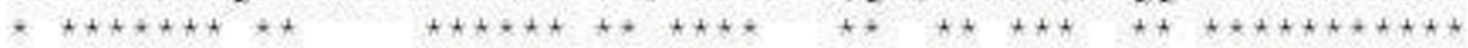

teIX NEMSDQNALLDFGQAAVEGVNATVNHILSEQKKLEI PQVDDLLKNTNRELNGFIAKYKDA teIA TFLADQNALLDFGQSAVEGVNATVNHILAEQKKLQIPQVDDLLKSTNRELNGFIAKYKDA

$t \quad+t+t+t+t+t+t+t+t+t+t+t+t+t+t+t+t+t+t+t+t+t+t+t+t+t+$

teIX SPADLEKKPNLIQKLEKQSKDSLQEFYFDSKSIEQKMDGMAAAVVKQEDTLARWIVSAEL

tEIA TPVDLDKKPNELQKLEKQSRDTLQEEYFDSQNIEQKMDSMAAAVVKOEDTLARNIVSAEL

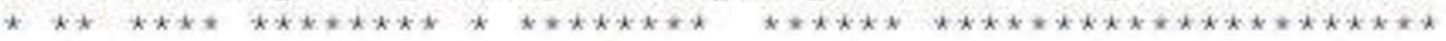

teIX LIEDNTKSIENLVGVIAFVEASQKEASARAVALQEELSTLESTTPQYQKISNQLARTTEV

LeIA LIEDNTKS IEHLVGVIAFIEASOKEASORAARLOKDLKTKDSTTPDYQIKADLIARTTEV

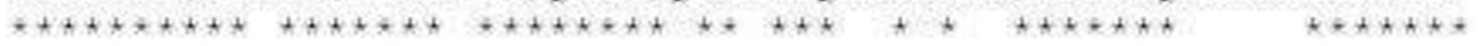

LEIX INTLEQOHTEYLSRMYVANATT POMRNLVKVSSDMROKLGMLRRNTI PTMKLAIAOLGML

tEIA INTLEQQHTEYLSRLYVAWATTPQMRNLVKVSSDMRQKLGMLRRNTI PTMKLSIAQLGMM

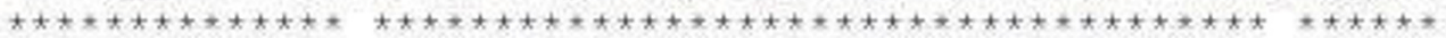

teIX QQSVKSGVTADAIVNANNAALOMLAETSKEAIPKLEQSAQGTTLSIQSVTALAESLVTQN

teIA QQSVKSGMTADAIVNANNAALOMLAETSKEAIPALEQSAQSPTLSMKSVTSLAESLVAQN

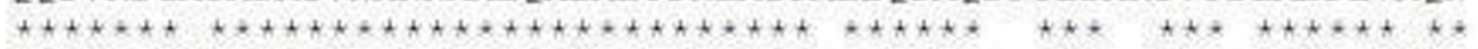

TEIX NGIIAAIDSGRQKRSQLEHAIIKSAETINDSVKLRDQKIVQALLDQGRTTQEDINN----

teIA NGITAAIDHGRKERAQLESAIIRSAETINDSVKLRDQNIVQALLSEGKETQKTIDKTTHA

$+t+t+t+t+t+t+t+t+t+t+t+t+t+t+t+t+t+t+t+t$
\end{abstract}

\title{
Figure 7
}

Amino acid alignment of tellurite resistance gene, telX, from S. iniae with S. pyogenes MGAS8232 telA. The proteins share $81 \%$ identity and $93 \%$ similarity. Asterisks indicate identical residues.

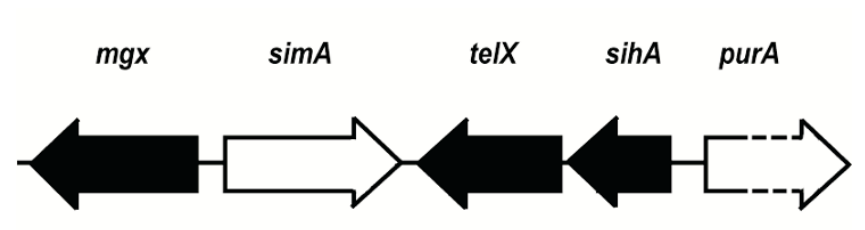

$500 \mathrm{nt}$

Figure 8

Genetic organization of the mgrX segment in S. iniae QMA0076.

\section{Discussion}

Evasion of phagocytosis is critical in the pathogenic strategies of many of the streptococci [9]. In S. iniae, capsule has been identified as a major virulence factor $[22,23]$ contributing to resistance to serum killing [24] and phagocytic evasion [25]. In other streptococci, binding of serum components by surface associated M-like proteins constitutes a major antiphagocytic mechanism. In the present study, we have demonstrated fibrinogen binding by whole $S$. iniae cells in vitro. Biotinylated fibrinogen that bound to the cell surface could be detected by fluorescence microscopy using fluorescein conjugated streptavidin. Because the fluorophore faded quickly under fluorescence microscopy an alternative dot-blot method was developed using an alkaline phosphatase conjugate. This enabled semi-quantitative evaluation of fibrinogen binding and indicated that strain QMA0141 bound less fibrinogen than QMA0076. This was supported by Western blots using the recombinantly expressed proteins from these strains and is reflected in the differing sim gene sequences of these isolates. As an indication of the potential role of fibrinogen binding by $S$. iniae, $S$. iniae cells 


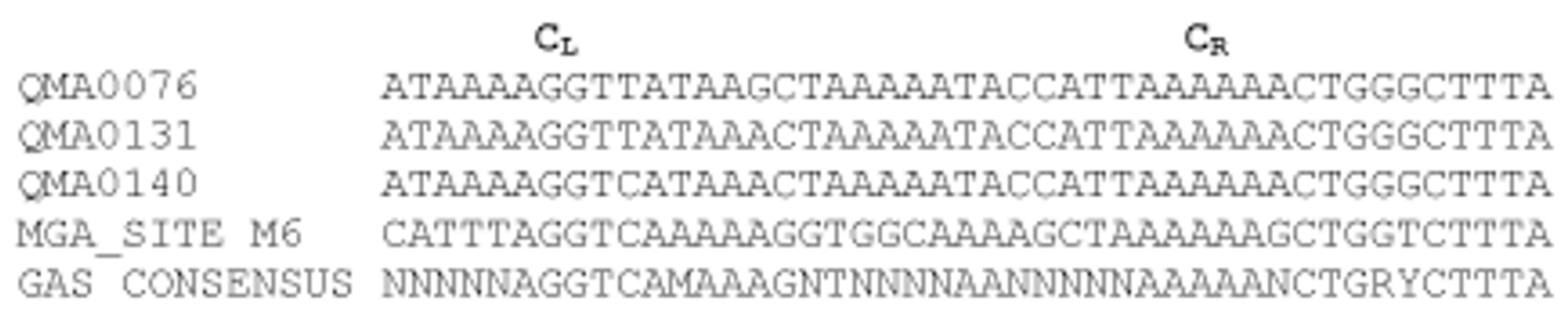

\section{Figure 9}

Alignment of putative Mgx binding sites upstream of simA genes. Alignment shows sequences from different isolates including Mga binding site and GAS consensus sequence (after Mclver et al., 1995).
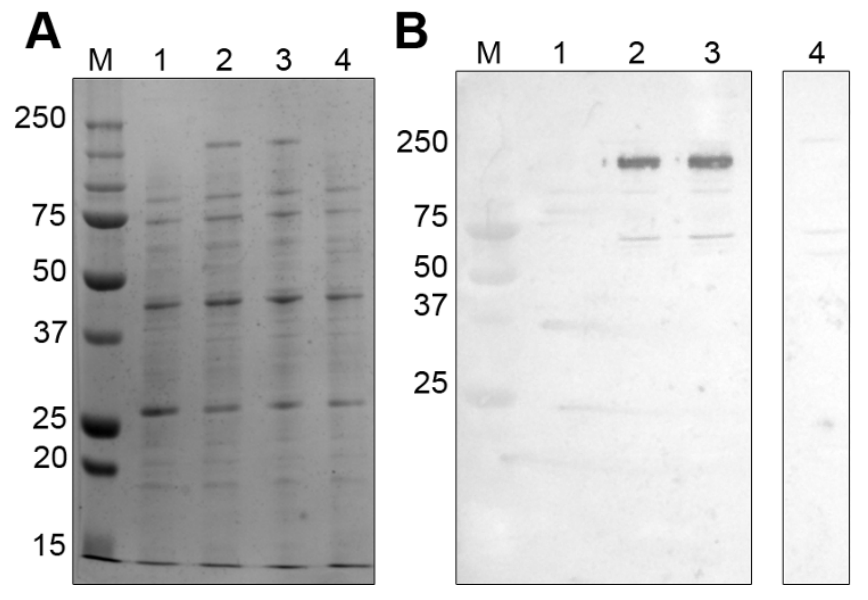

Figure 10

Western blot of SDS-PAGE separated lysates of $E$. coli expressing recombinant $M$ proteins. Lane $M-$ molecular weight marker, lane I - control lysate, lane 2 QMA0072, lane 3 - QMA0076, lane 4-QMA0I4I. A) Transferred lysates stained with Coomassie Brilliant Blue R250. B) Detection of recombinant SiM proteins in E. coli lysates with biotinylated fibrinogen.

incubated with fibrinogen prior to exposure to barramundi macrophages significantly reduced the subsequent respiratory burst of the macrophages, indicative of reduced phagocytosis.

Interestingly, fibrinogen binding was not detected when strains were grown overnight in vegetable peptone broth, and was only observed following growth on blood agar or in heat inactivated barramundi serum. This suggests that these proteins may be the same proteins previously reported to bind trout immunoglobulins, or are under the same regulatory control [26]. In the present study, we found a putative multigene regulator, encoded by $m g x$, upstream of the $\operatorname{sim} A$ or $\operatorname{sim} B$ gene. The sim genes from $S$. iniae are, in common with $\mathrm{emm}$ and $\mathrm{emm}$-like genes, most likely to be controlled by this multigene regulator; a $45 \mathrm{bp}$ putative DNA binding site for the Mgx protein lies between bases 184 and 140 upstream of the sim genes $[27,28]$ and overlaps the -35 RNA polymerase promoter box as has been determined for GAS [15]. Further studies are ongoing to determine if, as in GAS with Mga, the Mgx protein binds to this promoter region and activates transcription of sim and also to identify if Mgx is involved in its own regulation [29]. Additionally, the environmental conditions that govern regulation of these genes are being explored in order to optimise expression in culture.

The SiM proteins are quite different from previously reported M proteins in other streptococci, with the closest relative being the S. dysgalactiae dem gene at only $32 \%$ identity. In terms of the genetic organization of the $\mathrm{MgrX}$ segment, some similarities were found not only with GAS and GCS but also with the unusual S. uberis. In S. iniae the $m g x$ gene was organised in reverse orientation to the sim genes. This reversal has only been found to date in GES/ GBS S. uberis where the genetic organization of the multigene regulator and the lactoferrin binding protein are in opposite directions [16]. This differs from GAS, GCS and GGS where the orientation of the multigene regulatory and emm, emm-like and dem genes is in the same direction.

Similarities with GAS were found from the many genome sequencing projects from GAS serotypes M1, M3, M5, M6, M18 and M28 [27,28,30-34]. In all of these genomes, the genes for telA, Spy_0159 (and other names given to this hypothetical gene), and purA are located side by side and in the same relative transcriptional directions as $t e l X, \sin A$, and purA in S. iniae. The genes upstream of telA in GAS may be involved with energy production and conversion, however, downstream of the purA gene is a putative lipoprotein $\mathrm{ABC}$ transporter gene and a streptolysin $\mathrm{O}$ precur- 
sor gene, which may indicate a role in virulence for these genes. The roles of these homologous genes in $S$. iniae may also be similar, especially when their proximity to $m g x$ is considered, and the potential for other virulence factors that may be located nearby.

As evidenced by Western blotting of recombinant SiM proteins expressed in E. coli, the SiM protein from isolate QMA0076 appeared to bind the most fibrinogen, with that from isolate QMA0141 binding very little fibrinogen following transfer to the PVDF membrane. The one amino acid residue insertion after the intercoil region (in the second coiled region) of isolate QMA0072 did not appear to significantly disrupt the fibrinogen binding ability of the coils. It is interesting to note that all SiM protein sequences, regardless of size or divergence, contain the peptide sequence HEAIRSAGLE that connects the two coils. Conservation of this peptide indicates that it is likely to have a critical structural role for the binding of blood components such as fibrinogen and immunoglobulins [13] and needs to be investigated further. The signal peptide and $\mathrm{C}$ terminal ends were well conserved in all SiM types indicating that very little selective pressure has been exerted on these regions.

The ability to form tetrameric conglomerations may also be due to the coiled regions interacting with one another since the apparent molecular mass of $230 \mathrm{kDa}$ has also been observed with a fibrinogen binding protein from $S$. equi subsp. equi [12]. It is interesting to note that the ability of the SiM protein from isolate QMA0141, which had a much larger molecular weight, did not bind fibrinogen as efficiently as the major type. Given that other $\mathrm{M}$ and $\mathrm{M}$ like proteins are able to bind other blood proteins, the ability of these proteins to bind them also cannot be discounted. Indeed, a previous study reported binding of immunoglobulin from normal trout serum by $S$. iniae proteins of a similar molecular weight to the tetramers described in this study [26].

The lack of diversity of the sim genes present in our strain collection, which represents isolates from disparate geographic location and hosts, is surprising, especially when viewed in the context of emm gene sequence diversity found in GAS [35]. Only three gene types were found, with two of these types occurring only once each (Table 3 ). This may simply be a result of functional conservation, with sequence variation resulting in reduced binding capacity, as indicated in the present study with isolate QMA0141, leading to strains with this gene type to be relatively unsuccessful. An alternative hypothesis may be that there has been little or no selective pressure applied by the infected fish host to drive a change in this protein: perhaps as result of the organization of the fish immunogloblin light chains [36], they appear to be able to rec- ognise a less diverse repertoire of epitopes than their mammalian counterparts [37] and SiM proteins simply may not be immunogenic in fish. This is corroborated by previous work in trout and by observations in our own laboratory that antiserum from whole-cell immunised barramundi do not detect SiM proteins in Western blots (unpublished data). An alternative explanation is that once fish are infected with S. iniae, the opportunity to produce antibodies is negated by the short period of time between infection and death. The introduction of vaccination programmes against $S$. iniae into warm water aquaculture may provide the selective pressure required to drive evolution of further diversity in these genes.

In the present study, genes encoding a fibrinogen-binding M-like protein have been cloned, sequenced and expressed as recombinants for the first time from this pathogen of major importance in global aquaculture. It has been shown that members of the $M$ protein family contribute to virulence of Streptococcus sp., have the ability to bind blood components other than fibrinogen, and have a role in resistance to phagocytosis [9,11,12,38-41]. The present results support this observation, indicating that binding of fibrinogen by $S$. iniae reduced respiratory burst activity in fish macrophages. Moreover, an earlier study indicated proteins with a similar apparent molecular weight to those reported in this study are capable of binding trout immunoglobulins in reverse orientation (i.e. by the Fc region) [26]. Fibrinogen binding by S. iniae was only apparent in cultures grown on blood agar or in barramundi serum, indicating that $\mathrm{SiM}$ expression is likely to be environmentally regulated. Our identification of a putative regulatory protein and binding site upstream of the sim genes will enable further research into the control of these genes. The $\mathrm{M}$ protein is a major virulence factor and vaccine candidate in GAS [42-45] and future work is directed towards investigating the potential of a vaccine against $S$. iniae infection in farmed fish based on these intriguing proteins.

\section{Experimental Procedures}

\section{S. iniae strains and culture conditions}

Veterinary laboratory isolates of $S$. iniae taken from infected barramundi (Lates calcarifer), along with reference isolates from the Centers for Disease Control, Atlanta, and further global isolates were used in this study (Table 2). Strains in $20 \%$ glycerol that were stored at $80^{\circ} \mathrm{C}$ were grown overnight at $37^{\circ} \mathrm{C}$ on Columbia agar base containing $5 \%$ defibrinated sheep blood. For liquid cultures, $S$. iniae was grown in $10 \mathrm{ml}$ vegetable peptone broth (Oxoid, Basingstoke, UK) in sterile $15 \mathrm{ml}$ centrifuge tubes (Greiner Bio-One, Germany) statically at $37^{\circ} \mathrm{C}$. 


\section{Whole cell fibrinogen binding assay}

Human fibrinogen (Sigma, Castle Hill, Australia) was labelled using the EZ-Link Sulfo-NHS Biotinylation Kit (Pierce, Rockford, Il.) in accordance with the manufacturers instructions. Unincorporated biotin was removed using Micro-Spin G-25 columns (GE Healthcare Biosciences, North Ryde, Australia). Barramundi blood was collected by caudal venipuncture from $150 \mathrm{~g}$ fish using a $1 \mathrm{ml}$ tuberculin syringe fitted with a $23 \mathrm{G}$ needle. For serum, blood was allowed to clot for 24 hours at $4{ }^{\circ} \mathrm{C}$ to ensure complete removal of fibrinogen before centrifugation at $3000 \times g$ for $10 \mathrm{~min}$ to remove blood cells. For collection of plasma, $50 \mu \mathrm{L}$ ice-cold heparin $(10 \mathrm{U} / \mathrm{mL})$ was drawn into the syringe prior to blood collection. Blood cells were removed by centrifugation at $3000 \times g$ and plasma was either used immediately or stored at $-20^{\circ} \mathrm{C}$ until required.

S. iniae cultured overnight on blood agar, in $1 \mathrm{ml}$ heat inactivated barramundi serum or in vegetable peptone broth at $28^{\circ} \mathrm{C}$ was washed and suspended in phosphate buffered saline (PBS) to an optical density of 2.5 at 600 nm. Aliquots $(200 \mu \mathrm{L})$ were then incubated in Tris buffered saline (TBS) containing $5 \mu \mathrm{g} / \mathrm{mL}$ biotinylated fibrinogen, or in TBS alone as a control for $20 \mathrm{~min}$ at room temperature. Cells were harvested at $6,000 \times g$ for $5 \mathrm{~min}$ in a microcentrifuge and then washed six times in $1 \mathrm{~mL}$ TBS to remove any unbound fibrinogen. For fluorescence detection of bound fibrinogen, washed test and control cells were incubated with streptavidin-conjugated fluorescein isothiocyanate (FITC) diluted to $25 \mu \mathrm{g} / \mathrm{mL}$ in PBS for $30 \mathrm{~min}$. Cells were then washed eight times in PBS before resuspension in $50 \mu \mathrm{L}$ PBS. Aliquots $(10 \mu \mathrm{L})$ were then transferred onto washed glass microscope slides and covered with a glass cover slip. These wet mounts were then viewed under phase contrast using and Olympus BX41 epifluorescence microscope. As FITC fades rapidly upon UV exposure a procedure to eliminate exposure prior to capture was optimised as follows. Once a suitable field had been located under phase contrast it was photographed using the attached Olympus DP70 digital video camera. With the shutter between the stage and mercury vapour lamp closed to prevent UV exposure of the labelled cells, the FITC filter was moved into position and the camera setting adjusted manually to ISO800 and a shutter speed of 1.3s. The stage shutter was then opened to expose the cells to UV light and the image was captured simultaneously.

To support results obtained by fluorescence microscopy, a whole cell dot-blot method was used. In this method cells labelled with biotinylated fibrinogen and controls in TBS as described above were serially twofold diluted in TBS in a microtitre plate. A row containing serially diluted (from $2.5 \mu \mathrm{g} / \mathrm{mL}$ ) biotinylated fibrinogen was included as a pos- itive control. Aliquots $(5 \mu \mathrm{L})$ were then transferred to prewetted PVDF (Immobilon P, Millipore, UK) using a multichannel pipette and allowed to dry. The membrane was then blocked for 1 hour with $1 \%$ vitamin-free casein (Sigma, Castle Hill, Australia) in TBS containing 0.05\% Tween 20 (TBST). Following blocking, endogenous phosphatase activity was quenched with $20 \%$ acetic acid in distilled water for $5 \mathrm{~min}$. After $3 \times 5 \mathrm{~min}$ washes in TBST, the membrane was probed with alkaline phosphatase-conjugated streptavidin ( 0.2 units $/ \mathrm{mL}$ ) in TBST for $30 \mathrm{~min}$. The membrane was then washed $(\times 3)$ in TBST and then once in TBS before developing in a liquid phosphatase substrate (1-Step NBT/BCIP, Pierce, Rockford Il.) until the colour developed.

\section{Isolation and culture of peritoneal macrophages from barramundi}

Macrophages from casein stimulated peritoneal cavity were harvested, purified and maintained as described previously [46]. Briefly, for stimulation of the peritoneum, barramundi (Lates calcarifer) (300 g) were anaesthetisised with Aqui-S (Aquatic Diagnostic Services, Wilston, Australia) in accordance with the manufacturers instructions, and then injected with $1 \mathrm{~mL}$ of $12 \%$ casein (sterile, in phosphate buffered saline, PBS) into their peritoneal cavity $24 \mathrm{~h}$ before collection of macrophages. Prior to the isolation of peritoneal macrophages, fish were euthanised with overdose Aqui-S and then exsanguinated by cutting the ventral aorta. An aliquot (5 mL) L-15 medium containing 2\% Foetal Bovine Serum (FBS, Invitrogen, Melbourne, Australia), $1 \%$ penicillin/streptomycin $(\mathrm{P} / \mathrm{S})$ (Invitrogen, Melbourne, Australia), and $10 \mathrm{U} / \mathrm{mL}$ heparin (Sigma, Castle Hill, Australia) was injected aseptically into the peritoneal cavity using a syringe fitted with a 25 $\mathrm{G}$ needle. The body cavity was then massaged for $30 \mathrm{~s}$ to disperse the medium and the lavage containing leucocytes was withdrawn using 19 G syringe very carefully to prevent bleeding. The suspensions of peritoneal cells were then layered onto a discontinuous (34\%/51\%) Percoll density gradient and centrifuged at $450 \mathrm{~g}$ for $25 \mathrm{~min}$ at $4{ }^{\circ} \mathrm{C}$. The band lying at the interface was collected and washed twice with L-15 medium containing1\% FBS and $1 \% \mathrm{P} / \mathrm{S}$. Concentration of viable cells was determined by Trypan blue exclusion. The cells were seeded in microtiter plates at the concentration of $10^{7}$ cells $/ \mathrm{mL}$ in $\mathrm{L}-15$ medium with $1 \% \mathrm{FBS}$ and $1 \% \mathrm{P} / \mathrm{S}$. Cell populations were allowed to adhere for $2 \mathrm{~h}$ at $28^{\circ} \mathrm{C}$ and then washed twice with L-15 medium to remove the unattached cells. The adhered cells were maintained in L-15 with 1\% FBS and $1 \% \mathrm{P} / \mathrm{S}$ at $28^{\circ} \mathrm{C}$. For the assay, $24 \mathrm{~h}$ cultures were used.

\section{Induction of luminol-amplified chemiluminescence in peritoneal macrophages}

Streptococcus iniae strain QMA0072 was used for this assay. A suspension of cells taken directly from blood agar cul- 
tures $\left(\mathrm{OD}_{600}=1.5\right)$ was washed in PBS then pre-incubated in PBS, $5 \mu \mathrm{g} / \mathrm{mL}$ bovine serum albumen (BSA) in PBS, or $5 \mu \mathrm{g} / \mathrm{mL}$ fibrinogen in PBS for 30 minutes at $37^{\circ} \mathrm{C}$. The cells were then washed twice with HBSS and resuspended in HBSS.

The respiratory burst activity of the peritoneal macrophages following phagocytosis was determined using protocols described previously [47] with some modifications. Briefly, peritoneal macrophages, cultured for $24 \mathrm{~h}$, were incubated with either fibrinogen-treated, PBS-treated or BSA-treated S. iniae at a multiplicity of infection (MOI) of 100 (bacteria/macrophage ratio 100:1). The respiratory burst activity was initiated by the addition of $30 \mu \mathrm{L}$ of the required bacterial suspension to macrophages in microtitre plates $\left(1 \times 10^{5}\right.$ cells per well). To each well, $10 \mu \mathrm{L}$ of 10 $\mathrm{mM}$ luminol in $0.2 \mathrm{M}$ borate buffer $\mathrm{pH} 9.0$ and $280 \mu \mathrm{L}$ HBSS pH 7.4 were also added to get a final volume of 300 $\mu \mathrm{L}$. The chemiluminescence (CL) emissions of the phagocytes were measured in a luminometer/fluorometer (BMG Fluostar Optima, BMG Labtech, Offenberg, Germany) every 3 minutes for 3 hours at $27^{\circ} \mathrm{C}$.

\section{Recombinant DNA techniques}

$S$. iniae genomic DNA was extracted from freshly-grown cells using an enzymatic lysis method [7].

\section{PCR Amplification of S. iniae emm-like (sim) genes and cloning}

Each $50 \mu \mathrm{L}$ PCR tube contained $5 \mu \mathrm{L}$ of $10 \times$ Tth plus buffer, $1 \mu \mathrm{L}$ dNTP's $(4 \times 2.5 \mathrm{mM}$ of each of dATP, dCTP, dGTP and dTTP; Biotech International Ltd., Australia), $200 \mathrm{ng}$ of ALL MF and ALL MR primers (Table 1), $0.5 \mathrm{U}$ of Tth plus DNA polymerase (Biotech International Ltd., Australia), $3 \mu \mathrm{L}$ of $25 \mathrm{mM}$ magnesium chloride, and the balance made up with sterile Milli-Q water. Thermal cycling parameters in an Eppendorf Mastercycler Gradient EPS (Eppendorf, Hamburg, Germany) were denaturation for 2 mins at $94^{\circ} \mathrm{C}$ followed by 35 cycles of $50^{\circ} \mathrm{C}$ for 1 $\min , 72^{\circ} \mathrm{C}$ for $2 \mathrm{~min}$, and $94^{\circ} \mathrm{C}$ for $15 \mathrm{~s}$ with a final extension cycle of $50^{\circ} \mathrm{C}$ for $1 \mathrm{~min}$ and $72^{\circ} \mathrm{C}$ for $10 \mathrm{~min}$. The resultant PCR products were visualised after electrophoresis in a $1 \% \mathrm{w} / \mathrm{v}$ agarose gel containing $0.5 \mu \mathrm{L}$ of $10 \mathrm{mg} / \mathrm{mL}$ ethidium bromide solution in $1 \times$ TAE as the electrophoresis buffer.

Desired bands were excised from the gel and extracted from the agarose with the MegaSpin Agarose Gel Extraction Kit (Intron Biotechnology, Korea). Purified PCR products were ligated into PCR4-TOPO by TA cloning using a commercial kit (Invitrogen, Melbourne, Australia). Competent cells (TOP 10; Invitrogen, Melbourne, Australia) used in cloning experiments were cultured on Luria-Bertani Agar (LB Agar; Sigma, Castle Hill, Australia) supplemented with $100 \mu \mathrm{g} / \mathrm{mL}$ ampicillin. X-gal (40 $\mu \mathrm{l}$ of
$20 \mathrm{mg} / \mathrm{ml}$ ) was spread onto LB agar plates for blue-white discrimination. Clones were grown at $37^{\circ} \mathrm{C}$ overnight. Clones were picked using a sterile disposable loop and plated onto LB agar. These confirmed white clones were also used for screening by direct lysis PCR and for storage.

\section{Direct lysis PCR of clones and sequencing}

The reaction volume was scaled down to $25 \mu \mathrm{L}$, with the same reaction conditions as above. Use of plasmid-specific primers SP6 and T7 (Table 1) enabled the sim gene inserts to be amplified. Agarose gel electrophoresis allowed determination of clones with inserts, from which plasmids were extracted using a commercial kit in accordance with the manufacturers instructions (Invitrogen, Melbourne, Australia) for sequencing with plasmid primers SP6 and T7 (Table 1). Sequencing of the full length of the sim genes was initially facilitated with the primer SIM F (Table 1).

\section{Genome Walking and sim gene diversity}

Sequences upstream and downstream of the sim gene were obtained by genome walking according to the manufacturer's instructions (Genome Walker Kit, Clontech, Mountain View, Ca.). Gene specific primers used for genome walking upstream of the sim gene were SIM WR and SIM W2R (Table 1) and SIM WF and SIM W3F (Table 1). Resultant PCR products were gel-purified and ligated into TOPO vector PCRII (Invitrogen, Melbourne, Australia). Sequencing was carried out with SP6 and T7 primers on recombinant clones. This allowed primers to be designed (PRE SIM and POST SIM; Table 1) for the amplification of the sim genes and the surrounding spacers from additional strains (Table 2) to examine sim gene diversity. The same cycling parameters were used but with a $65^{\circ} \mathrm{C}$ annealing temperature and use of a proofreading polymerase enzyme system (Prime STAR DNA polymerase, Takara, Shiga, Japan) to reduce the likelihood of incorporation errors. The PRE SIM primer was located in the multigene regulator gene $(m g x)$ and included the first 36 nucleotides of the $m g x$ gene in the amplicons and the POST SIM primer included the last 75 nucleotides of the putative tellurite/toxic anion resistance gene $(t e l X)$. These PCR products were directly sequenced with the following primers: PRE SIM, SIM R, SIM 2R, SIM F, SIM 2F, SIM 3F, SIM W2R, and POST SIM (Table 1). Additionally, primers M141 F and SIM3 F RC were used to generate sequence data from isolate QMA0141.

\section{Expression of SiM proteins}

$M$ proteins were cloned for expression using the Champion pET system (pET101/D-TOPO; Invitrogen, Melbourne, Australia) and subsequently expressed in E. coli BL21 Star (DE3) One Shot chemically competent cells (Invitrogen, Melbourne, Australia) according to the man- 
ufacturer's instructions. Representatives of the different sim sequevars recovered were expressed according to the manufacturer's instructions. Representative isolates of the different sim genes QMA0072, QMA0076, and QMA0141 had their full proteins expressed.

To confirm fibrinogen binding activity of recombinantly expressed proteins, a Western blotting procedure was used. Lysates of recombinant E. coli described above were separated by SDS-PAGE in resolving gels containing 10\% acrylamide under reducing and non-reducing conditions. Resolved IPTG-induced cellular lysates were blotted onto PVDF membranes using a semi dry apparatus (Hoeffer Semi-Phor, GE Healthcare, North Ryde, NSW), the membranes were probed with biotinylated fibrinogen $(5 \mu \mathrm{g} /$ $\mathrm{mL}$ ) prepared as described above and detected using streptavidin-alkaline phosphatase (Pierce, Rockford, Il.) followed by colour development using 1-Step NBT-BCIP (Pierce, Rockford Il.).

\section{Nucleotide Sequence Accession Numbers}

GenBank accession numbers for sequences from this study are EU287919-EU287923.

\section{Authors' contributions}

JCFB discovered, characterised, and expressed the sim genes, discovered the surrounding genes, designed new molecular materials, drafted the manuscript and supervised AU. RAT contributed with macrophage assays and drafted part of the manuscript. AU contributed with PAGE and detection of proteins on western blots. ACB designed the study, conducted the fibrinogen binding assays, supervised RAT and revised the final manuscript. All authors have read and approved the final manuscript.

\section{Acknowledgements}

Justice Baiano is supported by Novartis Animal Vaccines Limited. Reiny Tumbol is supported by an AusAid scholarship. We thank the veterinary laboratories and veterinarians throughout Australia, Lynn Shewmaker of CDC, Atlanta, GA, and Christian Michel of INRA, Jouy-en-Josas, France for supply of strains.

\section{References}

I. Agnew W, Barnes AC: Streptococcus iniae: An aquatic pathogen of global veterinary significance and a challenging candidate for reliable vaccination. Vet Microbiol 2007, I 22(I-2): I- I 5 .

2. Shoemaker CA, Klesius PH, Evans J): Prevalence of Streptococcus iniae in tilapia, hybrid striped bass, and channel catfish on commercial fish farms in the United States. Am J Vet Res 200I, 62(2): $174-177$.

3. Weinstein MR, Litt M, Kertesz DA, Wyper P, Rose D, Coulter M, McGeer A, Facklam R, Ostach C, Willey BM, et al.: Invasive infections due to a fish pathogen, Streptococcus iniae. N EnglJ Med 1997, 337(9):589-594.

4. Facklam R, Elliott J, Shewmaker L, Reingold A: Identification and characterization of sporadic isolates of Streptococcus iniae isolated from humans. J Clin Microbiol 2005, 43(2):933-937.

5. Dey N, McMillan DJ, Yarwood PJ, Joshi RM, Kumar R, Good MF, Sriprakash KS, Vohra H: High diversity of group A Streptococcal emm types in an Indian community: the need to tailor multivalent vaccines. Clin Infect Dis 2005, 40(I):46-5I.
6. Geyer A, Schmidt $\mathrm{KH}$ : Genetic organisation of the $\mathbf{M}$ protein region in human isolates of group $\mathbf{C}$ and $\mathbf{G}$ streptococci: two types of multigene regulator-like (mgrC) regions. Mol Gen Genet 2000, 262(6):965-976.

7. Pruksakorn S, Sittisombut N, Phornphutkul C, Pruksachatkunakorn C, Good MF, Brandt E: Epidemiological Analysis of Non-MTypeable Group A Streptococcus Isolates from a Thai Population in Northern Thailand. J Clin Microbiol 2000, 38(3): I 250- I 254.

8. Pinho MD, Melo-Cristino J, Ramirez $M$ : Clonal relationships between invasive and noninvasive Lancefield group $\mathbf{C}$ and $\mathbf{G}$ streptococci and emm-specific differences in invasiveness. $J$ Clin Microbiol 2006, 44(3):84 I-846.

9. Courtney HS, Hasty DL, Dale JB: Anti-phagocytic mechanisms of Streptococcus pyogenes: binding of fibrinogen to M-related protein. Mol Microbiol 2006, 59(3):936-947.

10. Vohra H, Dey N, Gupta S, Sharma AK, Kumar R, McMillan D, Good MF: $M$ protein conserved region antibodies opsonise multiple strains of Streptococcus pyogenes with sequence variations in C-repeats. Res Microbiol 2005, I 56(4):575-582.

II. Meehan M, Lynagh Y, Woods C, Owen P: The fibrinogen-binding protein (FgBP) of Streptococcus equi subsp. equi additionally binds IgG and contributes to virulence in a mouse model. Microbiology 2001, I 47(Pt I 2):331 I-3322.

12. Meehan M, Nowlan P, Owen P: Affinity purification and characterization of a fibrinogen-binding protein complex which protects mice against lethal challenge with Streptococcus equi subsp. equi. Microbiology 1998, I44(Pt 4):993-1003.

13. Geyer A, Roth A, Vettermann S, Gunther E, Groh A, Straube E, Schmidt K: M protein of a Streptococcus dysgalactiae human wound isolate shows multiple binding to different plasma proteins and shares epitopes with keratin and human cartilage. FEMS Immunol Med Microbiol I999, 26(I): I I-24.

14. Carlsson F, Sandin C, Lindahl G: Human fibrinogen bound to Streptococcus pyogenes $M$ protein inhibits complement deposition via the classical pathway. Mol Microbiol 2005, 56(I):28-39.

15. Mclver KS, Heath AS, Green BD, Scott JR: Specific binding of the activator Mga to promoter sequences of the emm and scpA genes in the group A streptococcus. I Bacteriol 1995, i 77(22):6619-6624.

16. Moshynskyy I, Jiang M, Fontaine MC, Perez-Casal J, Babiuk LA, Potter AA: Characterization of a bovine lactoferrin binding protein of Streptococcus uberis. Microb Pathog 2003, 35(5):203-2I 5.

17. Vahling CM, Mclver KS: Domains required for transcriptional activation show conservation in the mga family of virulence gene regulators. J Bacteriol 2006, I 88(3):863-873.

18. Vasi J, Frykberg L, Carlsson LE, Lindberg M, Guss B: M-like proteins of Streptococcus dysgalactiae. Infect Immun 2000, 68(I):294-302.

19. Garnier J, Osguthorpe DJ, Robson B: Analysis of the accuracy and implications of simple methods for predicting the secondary structure of globular proteins. J Mol Biol 1978, I 20(I):97-I 20.

20. Lupas A: Prediction and analysis of coiled-coil structures. Methods Enzymol 1996, 266:513-525.

21. Lupas A, Van Dyke M, Stock J: Predicting coiled coils from protein sequences. Science I991, 252(50 I 0): I I62-I I 64.

22. Miller JD, Neely MN: Large-scale screen highlights the importance of capsule for virulence in the zoonotic pathogen Streptococcus iniae. Infect Immun 2005, 73(2):92I-934.

23. Buchanan JT, Stannard JA, Lauth X, Ostland VE, Powell HC, Westerman ME, Nizet V: Streptococcus iniae phosphoglucomutase is a virulence factor an a target for vaccine development. Infect Immun 2005, 73( I 0):6935-6944.

24. Barnes AC, Young FM, Horne MT, Ellis AE: Streptococcus iniae: serological differences, presence of capsule and resistance to immune serum killing. Dis Aquat Org 2003, 53(3):24I-247.

25. Locke JB, Colvin KM, Datta AK, Patel SK, Naidu NN, Neely MN, Nizet V, Buchanan JT: Streptococcus iniae Capsule Impairs Phagocytic Clearance and Contributes to Virulence in Fish. The Journal of Bacteriology 2007, I 89(4): I279- I 287.

26. Barnes AC, Horne MT, Ellis AE: Streptococcus iniae expresses a cell surface non-immune trout immunoglobulin-binding factor when grown in normal trout serum. Fish Shellfish Immunol 2003, I 5(5):425-43I. 
27. Banks DJ, Porcella SF, Barbian KD, Beres SB, Philips LE, Voyich JM, DeLeo FR, Martin JM, Somerville GA, Musser JM: Progress toward characterization of the group A Streptococcus metagenome: complete genome sequence of a macrolide-resistant serotype M6 strain. J Infect Dis 2004, 190(4):727-738.

28. Nakagawa I, Kurokawa K, Yamashita A, Nakata M, Tomiyasu Y, Okahashi N, Kawabata S, Yamazaki K, Shiba T, Yasunaga T, et al.: Genome sequence of an M3 strain of Streptococcus pyogenes reveals a large-scale genomic rearrangement in invasive strains and new insights into phage evolution. Genome Res 2003, I3(6A): 1042-1055.

29. Mclver KS, Thurman AS, Scott JR: Regulation of mga transcription in the group A streptococcus: specific binding of $\mathbf{m g a}$ within its own promoter and evidence for a negative regulator. J Bacteriol 1999, I 8 I ( I7):5373-5383.

30. Ferretti JJ, McShan WM, Ajdic D, Savic DJ, Savic G, Lyon K, Primeaux C, Sezate S, Suvorov AN, Kenton S, et al: Complete genome sequence of an MI strain of Streptococcus pyogenes. Proc Natl Acad Sci USA 200I, 98(8):4658-4663.

31. Beres SB, Richter EW, Nagiec MJ, Sumby P, Porcella SF, DeLeo FR, Musser JM: Molecular genetic anatomy of inter- and intraserotype variation in the human bacterial pathogen group $A$ Streptococcus. Proc Natl Acad Sci USA 2006, 103( 18):7059-7064.

32. Green NM, Zhang S, Porcella SF, Nagiec MJ, Barbian KD, Beres SB LeFebvre RB, Musser JM: Genome sequence of a serotype M28 strain of group a streptococcus: potential new insights into puerperal sepsis and bacterial disease specificity. J Infect Dis 2005, I 92(5): 760-770.

33. Holden MT, Scott A, Cherevach I, Chillingworth T, Churcher C Cronin A, Dowd L, Feltwell T, Hamlin N, Holroyd S, et al.: Complete genome of acute rheumatic fever-associated serotype M5 Streptococcus pyogenes strain manfredo. J Bacteriol 2007, | 89(4): | 1473-1477.

34. Smoot JC, Barbian KD, Van Gompel J], Smoot LM, Chaussee MS, Sylva GL, Sturdevant DE, Ricklefs SM, Porcella SF, Parkins LD, et al:: Genome sequence and comparative microarray analysis of serotype MI 8 group A Streptococcus strains associated with acute rheumatic fever outbreaks. Proc Natl Acad Sci USA 2002, 99(7):4668-4673.

35. Facklam RF, Martin DR, Lovgren M, Johnson DR, Efstratiou A Thompson TA, Gowan S, Kriz P, Tyrrell GJ, Kaplan E, et al.: Extension of the Lancefield classification for group $A$ streptococci by addition of 22 new $M$ protein gene sequence types from clinical isolates: emmI03 to emm I24. Clin Infect Dis 2002, 34(I):28-38

36. Hsu E, Criscitiello MF: Diverse immunoglobulin light chain organizations in fish retain potential to revise $B$ cell receptor specificities. J Immunol 2006, I77(4):2452-2462.

37. Mutharia LW, Raymond BT, Dekievit TR, Stevenson RMW: Antibody specificities of polyclonal rabbit and rainbow-trout antisera against Vibrio ordalii and serotype-0/2 strains of Vibrio anguillarum. Canadian Journal of Microbiology 1993 , 39(5):492-499.

38. Thern A, Wastfelt M, Lindahl G: Expression of two different antiphagocytic $M$ proteins by Streptococcus pyogenes of the OF+ lineage. J Immunol 1998, 160(2):860-869.

39. Podbielski A, Schnitzler N, Beyhs P, Boyle MD: M-related protein (Mrp) contributes to group A streptococcal resistance to phagocytosis by human granulocytes. Mol Microbiol 1996 , 19(3):429-44I.

40. Meehan M, Muldowney DA, O'Meara F, Owen P: Neither the Anor B-repeat regions of the fibrinogen-binding protein of Streptococcus equi subsp. equi are essential for fibrinogen binding. FEMS Microbiol Lett 2000, 190(2):317-32I.

41. Meehan M, Muldowney DA, Watkins NJ, Owen P: Localization and characterization of the ligand-binding domain of the fibrinogen-binding protein (FgBP) of Streptococcus equi subsp. equi. Microbiology 2000, I 46(Pt 5): I I87-1 I 94.

42. Batzloff MR, Pandey M, Olive C, Good MF: Advances in potential M-protein peptide-based vaccines for preventing rheumatic fever and rheumatic heart disease. Immunol Res 2006, 35(3):233-248.

43. Olive C: Progress in M-protein-based subunit vaccines to prevent rheumatic fever and rheumatic heart disease. Curr Opin Mol Ther 2007, 9(I):25-34.
44. Hu MC, Walls MA, Stroop SD, Reddish MA, Beall B, Dale JB: Immunogenicity of a 26-valent group $A$ streptococcal vaccine. Infect Immun 2002, 70(4):217I-2I 177.

45. Shaila MS, Nayak R, Prakash SS, Georgousakis M, Brandt E, McMillan DJ, Batzloff MR, Pruksakorn S, Good MF, Sriprakash KS: Comparative in silico analysis of two vaccine candidates for group A streptococcus predicts that they both may have similar safety profiles. Vaccine 2007, 25( I 8):3567-3573.

46. Do Vale A, Afonso A, Silva MT: The professional phagocytes of sea bass (Dicentrarchus labrax L.): cytochemical characterisation of neutrophils and macrophages in the normal and inflamed peritoneal cavity. Fish Shellfish Immunol 2002, 13(3): 183-198.

47. Nikoskelainen S, Verho S, Airas K, Lilius E-M: Adhesion and ingestion activities of fish phagocytes induced by bacterium Aeromonas salmonicida can be distinguished and directly measured from highly diluted whole blood of fish. Developmental \& Comparative Immunology 2005, 29(6):525-537.
Publish with Biomed Central and every scientist can read your work free of charge

"BioMed Central will be the most significant development for disseminating the results of biomedical research in our lifetime. "

Sir Paul Nurse, Cancer Research UK

Your research papers will be:

- available free of charge to the entire biomedical community

- peer reviewed and published immediately upon acceptance

- cited in PubMed and archived on PubMed Central

- yours - you keep the copyright 